\title{
Delayed Lumbar Artery Laceration and Symptomatic Retroperitoneal Hemorrhage Following IVC Filter Placement
}

\author{
Jennifer P. Montgomery, Kenneth J. Kolbeck \\ Dotter Interventional Institute, Oregon Health \& Science University, Portland, OR, USA \\ Email: jpmontgom@gmail.com
}

Received 24 June 2015; accepted 7 December 2015; published 10 December 2015

Copyright (C) 2015 by authors and Scientific Research Publishing Inc.

This work is licensed under the Creative Commons Attribution International License (CC BY).

http://creativecommons.org/licenses/by/4.0/

\section{(c) (i) Open Access}

\begin{abstract}
Inferior vena cava filters are placed in selected patients to protect against potentially fatal pulmonary embolism. Generally, filter placement is regarded as a safe procedure although rare complications may arise. Recurrent thromboembolic events are the most common complications associated with inferior vena cava filters; however, there are multiple reports of filter fracture, migration, embolization, penetration and perforation. The aim of this report is to illustrate a serious potential complication of inferior vena cava filters. We report a rare case of symptomatic retroperitoneal hemorrhage occurring 3 weeks after filter placement treated successfully with selective arterial embolization of a lumbar artery laceration. This case serves to highlight the importance of retrieving filters when they are no longer beneficial.
\end{abstract}

\section{Keywords}

Inferior Vena Cava Filter, Pulmonary Embolism, Hemorrhage, Arterial Embolization, Lumbar Artery Laceration

\section{Introduction}

The placement of inferior vena cava (IVC) filters has increased significantly since their inception, owing in some part to the use of retrievable IVC filters [1]. There are concerns, however, about the risk-benefit profile of retrievable IVC filters, particularly given low retrieval rates [2]. Retrievable filters are not without adverse events, including filter fracture, migration, IVC perforation, and IVC occlusion. A recent review of the MAUDE database reported the most common adverse event among retrievable IVC filters is fracture. The study recognizes that the most common type of adverse event encountered is dependent upon filter type [3]. Fortunately, 
symptomatic adverse events remain rare. We report a case of large retroperitoneal hemorrhage requiring transfusions thought to be the result of caval penetration and subsequent lumbar artery laceration by IVC filter.

\section{Case Report}

A 71-year-old Caucasian female with a past medical history of prior pulmonary embolism (PE) and deep venous thrombosis (DVT), asthma and morbid obesity presented to a referring hospital with acute onset, severe right flank pain. The patient had been recently discharged from our institution 2 weeks previously, following treatment for bilateral PE with right heart strain and ankle fracture. During the admission, she had undergone EKOS (Bothel, WA) catheter-directed thrombolysis and Cook Celect IVC filter (Bloomington, IN) placement. After successful venous thrombolysis, long term management included warfarin therapy for anticoagulation. No untoward events occurred at the time of initial lysis and IVC filter placement. At the time of discharge, the patient's INR was therapeutic at 2.3. The patient was scheduled for IVC filter removal in 1 month.

On presentation to the referring hospital, a non-contrast CT demonstrated a large retroperitoneal hemorrhage. The patient's INR was 3.0. The patient was transferred to our institution for further management. On arrival, the patient's vital signs were significant for a blood pressure of 76/49 $\mathrm{mmHg}$ and heart rate of $131 \mathrm{bpm}$. She was admitted to the intensive care unit and a CT angiogram (CTA) was performed, demonstrating active extravasation adjacent to the right L3 lumbar artery at the level of the IVC filter leg (Figure 1). The patient was then taken to the IR suite for further evaluation and management. An aortogram demonstrated an area of active arterial extravasation from the right L3 lumbar artery directly corresponding to findings on CTA. Selective catheterization and angiography of the right L3 lumbar artery with a reverse curve catheter demonstrated vessel rupture immediately adjacent to the IVC filter strut. Superselective catheterization of the L3 lumbar artery distal to the active bleeding was performed using a microcatheter and microwire. Digital subtraction angiography (DSA) demonstrated active extravasation (Figure 2). Microcoils were then deployed both distally and proximally to the laceration in the right L3 lumbar artery. Postembolization DSA confirmed occlusion of flow and no residual extravasation (Figure 3).

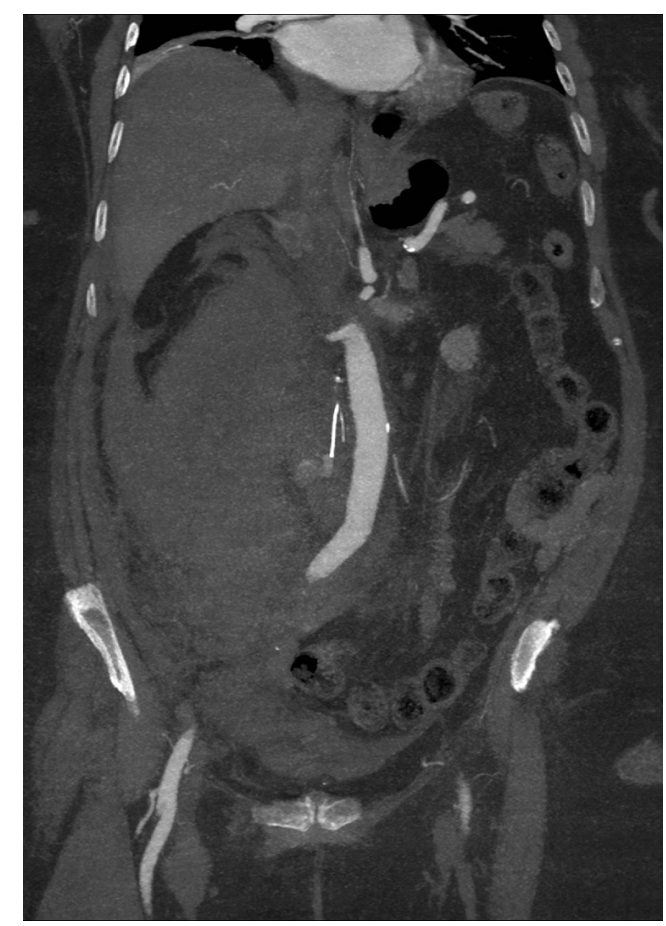

Figure 1. Coronal reconstruction of a CTA demonstrating a large right retroperitoneal hemorrhage and contrast extravasation immediately adjacent to the foot of the IVC filter at the expected level of the right L3 lumbar artery. 


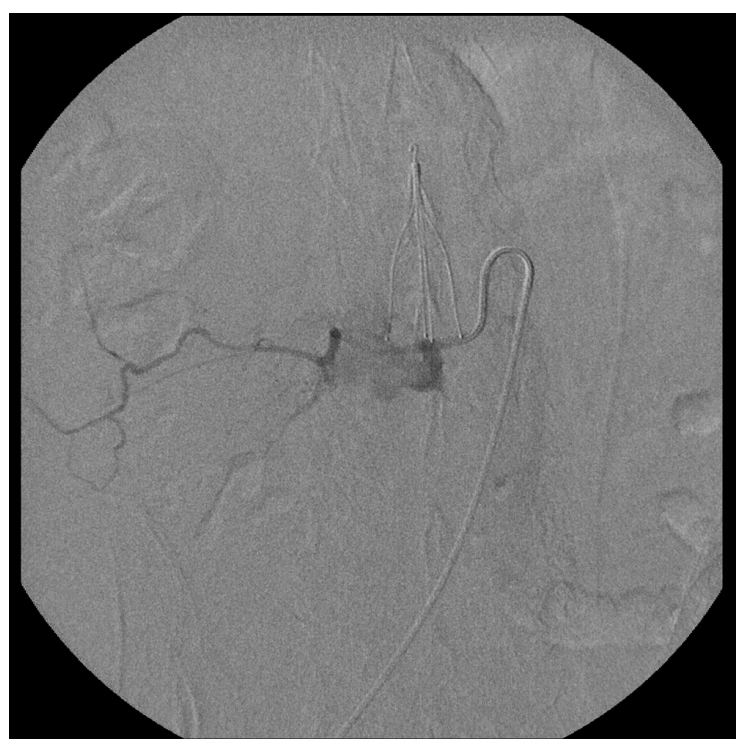

Figure 2. Selective DSA evaluation of the right L3 lumbar artery confirming the extravasation noted on CT.

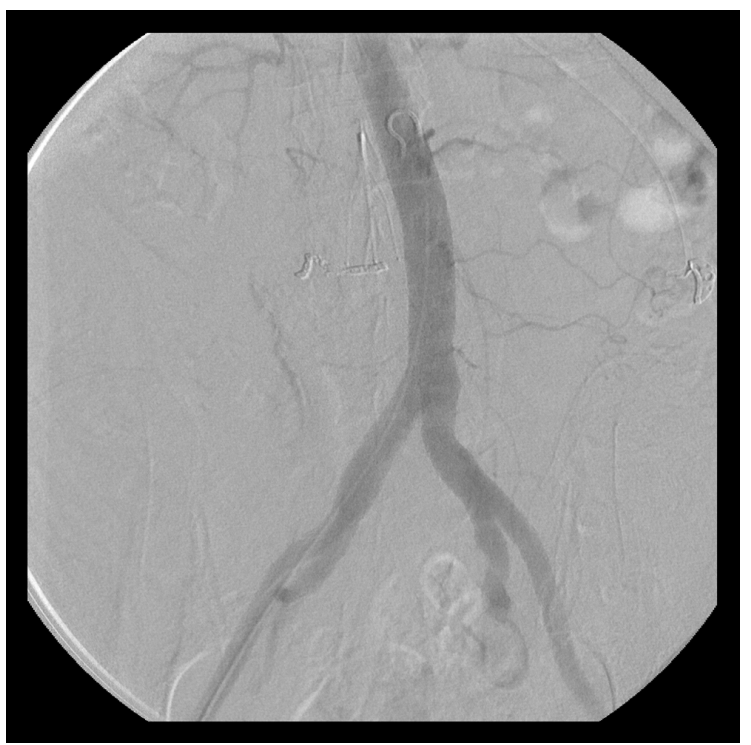

Figure 3. DSA evaluation of the aorta confirms the successful coil embolization of the lacerated artery.

Following embolization the patient's hematocrit remained stable. Venous duplex examination of the bilateral lower extremities revealed DVT in the right common femoral vein as well as the calf veins bilaterally. Patient was restarted on warfarin and discharged to a skilled nursing facility for further rehabilitation. The patient did will and once her INR was stable at a therapeutic level she was scheduled for IVC filter retrieval. The retrieval was uneventful. Interestingly, when the filter was sheathed and the legs captured, there was recoil motion of the embolic coils confirming the location of the filter leg against the lumbar artery.

\section{Discussion}

We present a case of symptomatic retroperitoneal hemorrhage following recent IVC filter placement. Retroperitoneal hemorrhage following IVC filter placement is a rare complication. Retroperitoneal hemorrhages may occur due to venous bleeding from caval wall disruption or may result from arterial laceration, as in our case 
[4]-[6]. One reported case of symptomatic arterial bleeding requires surgical intervention that reveals what appears to be a ruptured lumbar artery pseudoaneurysm in the vicinity of the stainless steel Greenfield filter (Boston Scientific, Marlborough, MA) strut [7]. The Gunther Tulip filter (Cook, Bloomington, IN) has been associated with two lumbar artery pseudoaneurysms. One report presented a small retroperitoneal hemorrhage in a patient with Klippel-Trenaunay syndrome who had the filter placed prophylactically and a second presented a large retroperitoneal hemorrhage in an anticoagulated patient, requiring embolization [8] [9]. More recently, there is a report of a retroperitoneal hemorrhage in the setting of a Bard Eclipse IVC filter (Tempe, AZ) placed 4 months previously, successfully treated conservatively, only to later demonstrate a lumber artery pseudoaneurysm requiring embolization [10].

Our study bolsters the growing evidence supporting the importance of removing IVC filters when no longer clinically beneficial. A literature review demonstrates that the vast majority of IVC filter related complications is associated with long-term use [2]. In fact, the U.S. Food and Drug Administration issues a safety communication advising the removal of retrievable IVC filters when the risk/benefit profile favors removal, suggesting removal between 29 and 54 days if the patient's transient risk for PE has passed [11] [12].

In our case, the patient receives a Cook Celect IVC filter (Bloomington, IN). While filter related complications has been reported for a multitude of IVC filter designs, the Celect vena cava filter has been associated with strut penetration in multiple publications. A recent single-center, retrospective review of 265 patients with Celect IVC filters demonstrates a strut penetration rate of $39 \%$ within 30 days and $80 \%$ within 90 days of placement by CT imaging [13]. Penetration into adjacent organs as assessed by CT occurs in 35 patients although all but one is asymptomatic. The same institution publishes a previous retrospective review of the Celect filter, demonstrating a penetration rate of $86 \%$ by cavogram [14]. Another retrospective review investigating Gunther Tulip and Celect retrievable filters, demonstrates a penetration rate of $93 \%$ for Celect filters by CT imaging although they do not report any symptomatic complications [15]. The Celect filter has also been implicated in asymptomatic aortic and lumbar arterial pseudoaneursym formation, following caudal migration, treated with stent-graft placement [16]. More recently, a retrospective, single-center study evaluates 595 Celect filters and finds CT evidence of strut penetration $>3 \mathrm{~mm}$ in $28.5 \%$ [17]. Of the filters demonstrating strut penetration, $34.5 \%$ have struts abutting or penetration adjacent organs. One patient has compression of the ureter with associated hydronephrosis, but there are no other cases with CT findings suggesting local complications. The study finds that a filter dwell time of longer than 100 days is statistically associated with strut penetration.

Our case serves to highlight a rare, but serious complication of IVC filter placement, symptomatic retroperitoneal hemorrhage. This illustrates the need for careful selection of patients that will benefit from filter placement, close observation of patients with IVC filters and timely removal of filters no longer needed.

\section{References}

[1] Keeling, A.N., Kinney, T.B. and Lee, M.J. (2008) Optional Inferior Vena Caval Filters: Where Are We Now? European Radiology, 18, 1556-1568. http://dx.doi.org/10.1007/s00330-008-0923-z

[2] Angel, L.F., Tapson, V., Galgon, R.E., Restrepo, M.I. and Kaufman, J. (2011) Systematic Review of the Use of Retrievable Inferior Vena Cava Filters. Journal of Vascular and Interventional Radiology, 22, 1522-1530. http://dx.doi.org/10.1016/j.jvir.2011.08.024

[3] Andreoli, J.M., Lewandowski, R.J., Vogelzang, R.L. and Ryu, R.K. (2014) Comparison of Complication Rates Associated with Permanent and Retrievable Inferior Vena Cava Filters: A Review of the MAUDE Database. Journal of Vascular and Interventional Radiology, 25, 1181-1185. http://dx.doi.org/10.1016/j.jvir.2014.04.016

[4] Wang, W., Spain, J. and Tam, M.D. (2011) Acute Abdominal Pain after Retrievable Inferior Vena Cava filter Insertion: Case Report of Caval Perforation by an Option Filter. Cardio Vascular and Interventional Radiology, 34, 883-885. http://dx.doi.org/10.1007/s00270-010-0080-z

[5] Satya, R., Anderson, J., Lievano, G. and Satya, R.J. (2009) Inferior Vena Cava (IVC) Rupture and Retroperitoneal Hemorrhage Caused by IVC Filter Migration. Journal of Vascular and Interventional Radiology, 20, 1102-1104. http://dx.doi.org/10.1016/j.jvir.2009.05.001

[6] Brown, A.P., Miller, M.J. and Smith, T.P. (2007) Caval Penetration with Retroperitoneal Hemorrhage Following Placement of an Inferior Vena Cava (IVC) Filter. Seminars in Interventional Radiology, 24, 312-315. http://dx.doi.org/10.1055/s-2007-985741

[7] Woodward, E.B., Farber, A., Wagner, W.H., et al. (2002) Delayed Retroperitoneal Arterial Hemorrhage after Inferior Vena Cava (IVC) Filter Insertion: Case Report and Literature Review of Caval Perforations by IVC Filters. Annals of Vascular Surgery, 16, 193-196. http://dx.doi.org/10.1007/s10016-001-0150-4 
[8] Dillon, B.J. and Alomari, A.I. (2008) Lumbar Artery Pseudoaneurysm Following Inferior Vena Cava Filter Placement. Journal of Vascular and Interventional Radiology, 19, 1673-1674. http://dx.doi.org/10.1016/j.jvir.2008.08.003

[9] Skeik, N., McEachen, J.C., Stockland, A.H., et al. (2011) Lumbar Artery Pseudoaneurysm Caused by a Gunther Tulip Inferior Vena Cava Filter. Vascular and Endovascular Surgery, 45, 756-760. http://dx.doi.org/10.1177/1538574411419373

[10] Tsekouras, N., Whalen, R.C. and Comerota, A.J. (2015) Lumbar Artery Pseudoaneurysm in a Patient with Inferior Vena Cava Filter and History of Strenuous Physical Exercise. Journal of Vascular Surgery, 61, 796-799. http://dx.doi.org/10.1016/j.jvs.2013.09.057

[11] U. S. Food and Drug Administration (2014) Removing Retrievable Inferior Vena Cava Filters: FDA Safety Communication. U. S. Food and Drug Administration.

[12] Morales, J.P., Li, X., Irony, T.Z., Ibrahim, N.G., Moynahan, M. and Cavanaugh Jr., K.J. (2013) Decision Analysis of Retrievable Inferior Vena Cava Filters in Patients without Pulmonary Embolism. Journal of Vascular Surgery: Venous and Lymphatic Disorders, 1, 376-384. http://dx.doi.org/10.1016/j.jvsv.2013.04.005

[13] Zhou, D., Moon, E., Bullen, J., Sands, M., Levitin, A. and Wang, W. (2014) Penetration of Celect Inferior Vena Cava Filters: Retrospective Review of CT Scans in 265 Patients. American Journal of Roentgenology, 202, 643-647. http://dx.doi.org/10.2214/AJR.13.11097

[14] Zhou, D., Spain, J., Moon, E., McLennan, G., Sands, M.J. and, Wang, W. (2012) Retrospective Review of 120 Celect Inferior Vena Cava Filter Retrievals: Experience at a Single Institution. Journal of Vascular and Interventional Radiology, 23, 1557-1563. http://dx.doi.org/10.1016/j.jvir.2012.08.016

[15] Durack, J.C., Westphalen, A.C., Kekulawela, S., et al. (2012) Perforation of the IVC: Rule Rather than Exception after Longer Indwelling Times for the Gunther Tulip and Celect Retrievable Filters. CardioVascular and Interventional Radiology, 35, 299-308. http://dx.doi.org/10.1007/s00270-011-0151-9

[16] Pham, J.D., Huang, S.Y., Sabir, S.H., Huynh, T. and, Wallace, M.J. (2014) Celect Filter Penetration of Aorta and Lumbar Artery. Journal of Vascular and Interventional Radiology, 25, 487-490.

[17] Bos, A., Van Ha, T., van Beek, D., et al. (2015) Strut Penetration: Local Complications, Breakthrough Pulmonary Embolism, and Retrieval Failure in Patients with Celect Vena Cava Filters. Journal of Vascular and Interventional Radiology, 26, 101-106. 